\title{
SAR interferometry using ALOS-2 PALSAR-2 data for the Mw 7.8 Gorkha, Nepal earthquake
}

\author{
Ryo Natsuaki', Hiroto Nagai, Takeshi Motohka, Masato Ohki, Manabu Watanabe, Rajesh B. Thapa, \\ Takeo Tadono, Masanobu Shimada and Shinichi Suzuki
}

\begin{abstract}
The Advanced Land Observing Satellite-2 (ALOS-2, "DAICHI-2") has been observing Nepal with the Phased Array type L-band Synthetic Aperture Radar-2 (PALSAR-2) in response to an emergency request from Sentinel Asia related to the Mw 7.8 Gorkha earthquake on April 25, 2015. PALSAR-2 successfully detected not only avalanches and local crustal displacements but also continental-scale deformation. Especially, by the use of the ScanSAR mode, we are able to make interferograms that cover the entire displacement area of the earthquake. However, we did encounter some fundamental problems with the ScanSAR and incorrect settings of PALSAR-2 operation that have now been fixed. They include (1) burst overlap misalignment between two ScanSAR observations, which limits the number of pairs available and the quality of the interferogram, (2) non-crustal fringes which are derived from co-registration error and/or ionospheric effect and, (3) incorrect setting of the center frequency in the Stripmap beam F2-6. In this paper, we describe their problems and solutions. The number of interferometric pairs are limited by (1) and (3). The accuracy of the interferograms are limited by (2) and (3). The experimental results showed that current solutions for (2) and (3) work appropriately.
\end{abstract}

Keywords: Gorkha earthquake, ALOS-2, PALSAR-2, InSAR, Synthetic Aperture Radar (SAR), ScanSAR interferometry, Stripmap-ScanSAR interferometry

\section{Introduction}

Interferometric Synthetic Aperture Radar (InSAR) becomes one of the essential technologies for rapid analysis of ground displacements (Boerner 2003). Combined with real-time GPS monitoring, it enables us to observe and assess the ground displacement over large areas. The Phased Array type L-band Synthetic Aperture Radar-2 (PALSAR-2) aboard the Advanced Land Observing Satellite-2 (ALOS-2, "DAICHI-2") is the latest L-band spaceborne SAR operated by the Japan Aerospace Exploration Agency (JAXA) (Arikawa et al. 2014; Shimada and Osawa 2012). The ALOS-2 has worldwide observation scenarios for various missions, e.g., detection of deformation, monitoring forest change, and monitoring sea ice. Its precise orbit control and the gallium nitride

*Correspondence: natsuaki.ryo@jaxa.jp

Earth Observation Research Center, Japan Aerospace Exploration Agency,

2-1-1 Sengen, Tsukuba, 305-8505 Ibaraki, Japan
$(\mathrm{GaN})$ high-power transmitter/receiver enable accurate analyses in high spatial resolution. The ALOS-2 has a frequent 14-day revisit cycle, which is three times faster than the previous ALOS (46-day cycle). Because of the limitation in swath width, the scheduled cycle in the basic observation scenario is longer than 14 days. However, once a large disaster occurred, ALOS-2 is so planned to observe the affected area in every revisit cycle for specific duration. PALSAR-2 uses mainly two modes for worldwide observation. One is the $10-\mathrm{m}$ resolution and 70-km swath Stripmap (swath) mode and the other is the $350 \mathrm{~km}$ swath ScanSAR mode. The 3-m resolution Stripmap mode and the $1 \times 3 \mathrm{~m}$ resolution spotlight mode can be used situationally. As a duty of the disaster response mission, ALOS-2 was used to observe the area affected by the Mw 7.8 Gorkha, Nepal earthquake and its aftershocks. These results were provided to Nepal through, for example, the International Charter on Space and Major Disasters, Sentinel Asia, and International

\section{Springer}

(c) Natsuaki et al. 2017 Open Access This article is distributed under the terms of the Creative Commons Attribution 4.0 International License (http://creativecommons.org/licenses/by/4.0/), which permits unrestricted use, distribution, and reproduction in any medium, provided you give appropriate credit to the original author(s) and the source, provide a link to the Creative Commons license, and indicate if changes were made. 
Centre for Integrated Mountain Development (ICIMOD) for the detection of severely affected areas. At the same time, such datasets are used for crustal deformation monitoring by interferometric analysis. By the use of the inversed displacement model from near real-time GPS observation, SAR satellites could aim to observe the most affected area in Nepal.

This paper contains two main experimental results using ALOS-2 data. One pertains to ScanSAR-ScanSAR interferometric analysis and the other pertains to interferometric analysis using Stripmap images of beam no. F2-6. We first describe in the next section ScanSARScanSAR interferometry for PALSAR-2. As PALSAR-2 had a burst overlap problem until February 8, 2015, the number of paths that have appropriate archives is limited. Another problem is that the wide and long swath image contains non-crustal fringes more visibly than with the other modes. That is, dozens of non-crustal fringes which do not relate to the orbit nor topography remain in the interferogram.

Next, we describe a problem in the Stripmap mode beam no. F2-6. The center frequency of this beam was set incorrectly until June 1, 2015. As the frequency band of this beam did not overlap with the other modes/beams, the performance of interferometric analysis using this beam is limited. Unfortunately, path 157 covers Kathmandu with this beam. Here, we show as an example the interferogram generated from the pre- and post-June 1 observations. We also show the StripmapScanSAR interferogram. As JAXA basically provides L1.1 Single Look Complex (SLC) images, we have to reprocess the SLC data before co-registration.

In the last section, we conclude this article. Note that all interferograms in this paper are slant-range images and are not geocoded, because the main purpose of this article is not the measurement of deformation itself but rather how to compute clear interferograms. We also did not apply any filters to the interferograms, except for multilooking so that we could show the interferograms at their lowest quality.

\section{ScanSAR-ScanSAR interferometry}

In this section, we report the performance of PALSAR-2 ScanSAR-ScanSAR interferometry for the monitoring of the Mw 7.8 Gorkha, Nepal earthquake on April 25, 2015 (USGS 2016a). In response to the earthquake, ALOS2 observed Nepal to acquire coseismic interferometric pairs.

The first coseismic ScanSAR image was taken from path 47 on April 28, 2015, three days after the event. Unfortunately, the coverage of this path was limited to the east end of the deformation area. The deformation area was observed fully on May 3, 2015, from path 48. In this section, we describe three major technical problems, and their solutions, of the PALSAR-2 ScanSAR interferometry. These problems are burst overlap, co-registration, and non-crustal low-frequency fringes. The following subsections describe in turn each problem and its solutions.

\section{Burst overlap problem}

To perform ScanSAR-ScanSAR interferometry, the timing of the radio wave transmission (burst) should be almost the same (Bamler and Eineder 1996; Guarnieri and Prati 1996). According to the experiments in previous ALOS ScanSAR data, if each burst duration has an overlap more than $20 \%$, faint fringes can be seen in an interferogram (Liang et al. 2013; Tong et al. 2010). For numerical analysis, at least $50 \%$ of the burst overlap is required (Buckley and Gudipati 2011). ALOS-2 achieves these requirements by its autonomous navigation system which is designed to flight in horizontal baseline smaller than $500 \mathrm{~m}$ and with along-track position accuracy smaller than $10 \mathrm{~m}$ (Kankaku et al. 2009). In this case, the burst overlap ratio is expected to be larger than $90 \%$ in 1 sigma, i.e., a pair of SLCs has the burst overlap ratio more than $90 \%$ with a probability of $68.3 \%$.

However, the parameter for estimating the latitude (the along-track position) of the satellite was set incorrectly until the modification made on February 8, 2015. This problem led to the burst overlap ratio being dependent on the acquisition dates of the two SLCs. JAXA announced that the along-track shift can be calculated by the following equation (ALOS-2 Project Team 2015b). This equation is derived from the orbital record of ALOS-2. They re-calculated the difference of the actual and the incorrectly set burst alignment positions. Note that this incorrect position parameter is used only for the ScanSAR burst alignment and is not used for the other functions such as the orbit definition of ALOS-2.

$B_{\mathrm{deg}}(D)=a_{4} \Delta D^{4}+a_{3} \Delta D^{3}+a_{2} \Delta D^{2}+a_{1} \Delta D^{1}+a_{0}$

Where $B_{\operatorname{deg}}(D)$ is the burst offset in degree latitude at day $D, \Delta D$ is the date difference between $D$ and August 4, 2014 in days, and the coefficients $a_{0}-a_{4}$ are $[-0.057085827546,-0.001106963087,0.000010685720$, $0.000000029289,-0.000000000194]$, respectively. As the cycle of the burst for beam no. W2 is 0.048348 [deg], $\bmod \left[B_{\operatorname{deg}}(D), 0.048348\right]$ is the estimated azimuth shift required for the interferometry. The results for the overlap date are shown in (ALOS-2 Project Team 2015b).

Lindsey et al. (2015) independently analyzed the burst overlap ratio from the ALOS-2 archive SLCs and found sinusoidal oscillation that was approximately the same as the official one. They counted the actual offset of two SLC images by cross-correlation co-registration and fit it to the sine function. Their model for the azimuth shift estimation is 


$$
B_{\text {pix }}(D)=\bmod [A \sin (2 \pi \Delta D / T)+P, 2 P]-P
$$

where $B_{\text {pix }}(D)$ is the burst offset in pixels at day $\mathrm{D}, \Delta D$ is the date difference between $D$ and December 20, 2014 in days, and the period $T=365$ days. $\bmod []$ is the modulo operation. The best-fitting parameters for the beam no. W2, L1.1 standard product are amplitude $A=3635$ and $P=1050$ pixels for the sub-swaths $\mathrm{F} 1$. The remaining subswaths have overlapped if F1 has overlapped.

The burst overlap ratio $R$ is calculated simply from Eq. 2 as

$$
R=1-\left|\frac{B(D)}{P}\right|
$$

The JAXA official equation is a polynomial equation in degree, whereas the Lindsey et al. equation is a sine equation in pixel. To compare these equations, we converted Eq. 1 to pixel scale. As one cycle of the burst is equal to 0.048348 [deg] and 2100 [pixel], the conversion equation is

$$
B_{\text {pix }}(D)=\frac{2100}{0.048348} B_{\text {deg }}(D)
$$

Figure 1 shows the comparison between two predictions and the actual offsets used in Lindsey et al. (2015). The blue rhombuses predicted by Lindsey et al. 2015 and the red squares predicted by (ALOS-2 Project Team 2015b) have a slight difference at the beginning and the end of the software incorrectly set period. This is simply the difference of the polynomial approximation and the sine approximation. Both equations are valid from the start of the ALOS-2 mission until February 8, 2015 modification. We calculated the root-mean-squared error (RMSE) of these two predictions in sub-swath F1. The results are 48.76 pixels for Lindsey et al. (2015) and 52.67 pixels for ALOS-2 Project Team (2015b), respectively. In short, two predictions have almost the same accuracy compared to the burst duration of 420 pixels.

For the Gorkha earthquake, crustal deformation could be observed by PALSAR-2 from five independent paths, paths 47-49 and paths 156 and 157, for the descending and the ascending node, respectively. The Paths and their frames on the map are shown in Fig. 2. According to the previous two estimations, no pre-February 8 SLC has enough burst overlap ratio. Fortunately, paths 47 and 48 have post-February 8 archives which are acquired prior to the earthquake. On the other hand, paths 49 and 157 have records which have no burst overlap (ALOS2035063050150116 and ALOS2011480550-140809, respectively) and, path 156 has no ScanSAR record prior to the earthquake. Tables 1 and 2 show the acquisition records and the potential for interferometric analysis (burst overlap > $20 \%$ ) for the paths 47 and 48, respectively.

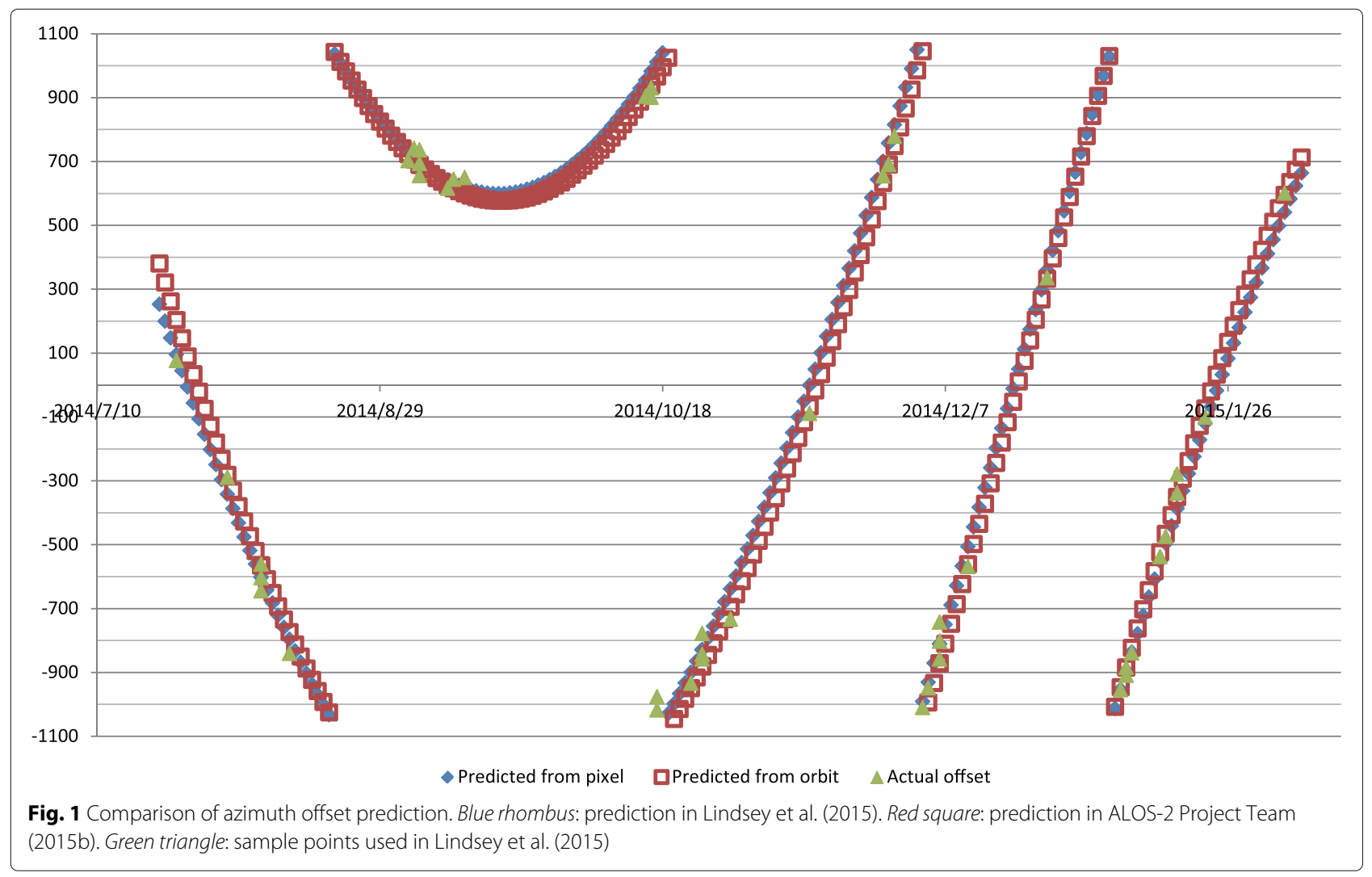




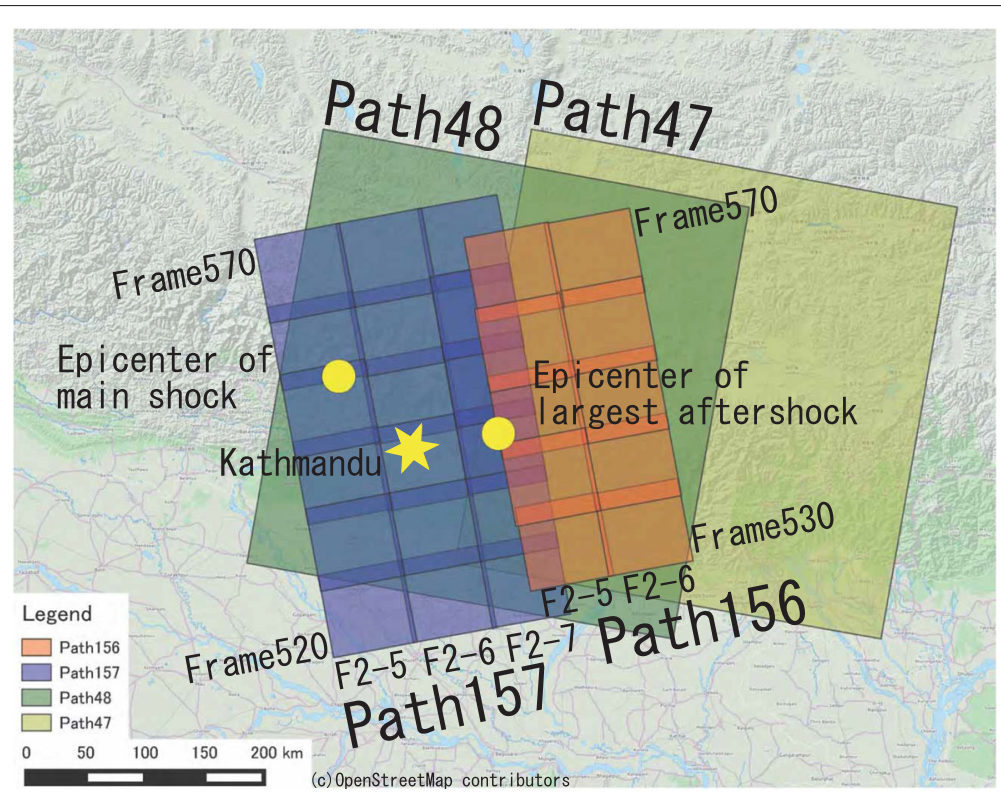

Fig. 2 Path and frame numbers on the map. Red: path 156 (ascending), frames 530-570. Blue: path 157 (ascending), frames 520-570. Brown: path 47 (descending), frame 3050. Green: path 48 (descending), frame 3050 and. Yellow dots: epicenter of the main (N 28.230, E 84.731) (USGS 2016a) and the largest aftershock (N 27.809, E 86.066) (USGS 2016b)

\section{Co-registration for PALSAR-2 ScanSAR interferometry}

If the ScanSAR SLCs are burst aligned, it is possible to make an interferogram from them. Currently, ALOS-2 provides SLC level 1.1 or higher level products. Two compression methods are available (ALOS-2 Project Team 2014): a so called "full-aperture mode" or Stripmap equivalent range-Doppler algorithm (Bamler and Eineder 1996) and spectral analysis (SPECAN)-based method (Lanari et al. 1998; Sack et al. 1985). The detail of the SAR-focusing algorithms are described by Cumming and Wong (2005). In both case, a level 1.1 ScanSAR product is divided into 5 and 7 sub-swath SLCs for 350 and $490 \mathrm{~km}$ total swath, respectively. Each sub-swath has its own pulse repetition frequency (PRF) from 2270 to $3314 \mathrm{~Hz}$. The burst cycle and its duration are 0.79 and $0.158 \mathrm{~s}$ for all sub-swaths, respectively. In this subsection, the word "SLC" is used in the sub-swath scale and not the total ScanSAR image because an ALOS-2 level 1.1 product contains multiple SLCs corresponding to each sub-swaths. If the SLCs are created in full-aperture mode, an accurate co-registration is necessary, as for Stripmap interferometry. However, the ALOS-2 standard ScanSAR SLC has multiple peaks cyclically in azimuth direction for its autocorrelation function (ACF) due to the padding zeros in the azimuth compression (Bamler and Eineder 1996; Holzner and Bamler 2002). That is, a cross-correlation function between two SLC images, namely "master" and "slave," has discrete cross-correlation peaks in different parts of the image. This phenomenon worsens the co-registration accuracy.

Table 1 ScanSAR observation record and potential of interferometric analysis for path 47 by June 2015

\begin{tabular}{|c|c|c|c|c|c|c|c|c|c|c|}
\hline \multirow[t]{2}{*}{ Number } & \multirow[t]{2}{*}{ Scene ID } & \multirow[t]{2}{*}{ Date } & \multicolumn{8}{|c|}{ Potential } \\
\hline & & & 1 & 2 & 3 & 4 & 5 & 6 & 7 & 8 \\
\hline 1 & ALOS2012883050-140819 & August 19, 2014 & - & $\mathrm{N}$ & Y & $\mathrm{N}$ & $\mathrm{N}$ & $\mathrm{N}$ & N & $\mathrm{N}$ \\
\hline 2 & ALOS2014953050-140902 & September 2, 2014 & $N$ & - & $\mathrm{N}$ & $\mathrm{N}$ & N & $\mathrm{N}$ & N & $\mathrm{N}$ \\
\hline 3 & ALOS2033583050-150106 & January 6, 2015 & Y & $\mathrm{N}$ & - & $\mathrm{N}$ & $\mathrm{N}$ & $\mathrm{N}$ & N & $\mathrm{N}$ \\
\hline 4 & ALOS2039793050-150217 & February 17, 2015 & $N$ & $\mathrm{~N}$ & $\mathrm{~N}$ & - & Y & Y & Y & Y \\
\hline 5 & ALOS2046003050-150331 & March 31, 2015 & $\mathrm{~N}$ & $\mathrm{~N}$ & $\mathrm{~N}$ & Y & - & Y & Y & Y \\
\hline 6 & ALOS2050143050-150428 & April 28, 2015 & $\mathrm{~N}$ & $\mathrm{~N}$ & $\mathrm{~N}$ & Y & Y & - & Y & Y \\
\hline 7 & ALOS2052213050-150512 & May 12,2015 & $\mathrm{~N}$ & $\mathrm{~N}$ & $\mathrm{~N}$ & Y & Y & Y & - & Y \\
\hline 8 & ALOS2058423050-150623 & June 23, 2015 & $\mathrm{~N}$ & $\mathrm{~N}$ & $\mathrm{~N}$ & Y & Y & Y & Y & - \\
\hline
\end{tabular}

"Y" and " $\mathrm{N}$ " represent "have" and "do not have" the potential for interferometric analysis (burst overlap $>20 \%$ ), respectively 
Table 2 ScanSAR observation record and potential of interferometric analysis for path 48 by June 2015

\begin{tabular}{|c|c|c|c|c|c|c|c|c|c|}
\hline \multirow[t]{2}{*}{ Number } & \multirow[t]{2}{*}{ Scene ID } & \multirow[t]{2}{*}{ Date } & \multicolumn{7}{|c|}{ Potential } \\
\hline & & & 1 & 2 & 3 & 4 & 5 & 6 & 7 \\
\hline 1 & ALOS2011553050-140810 & August 10, 2014 & - & $\mathrm{N}$ & $N$ & N & N & N & $\mathrm{N}$ \\
\hline 2 & ALOS2028113050-141130 & November 30, 2014 & $\mathrm{~N}$ & - & $\mathrm{N}$ & N & N & N & N \\
\hline 3 & ALOS2040533050-150222 & February 22, 2015 & $\mathrm{~N}$ & $\mathrm{~N}$ & - & Y & Y & Y & Y \\
\hline 4 & ALOS2046743050-150405 & April 5, 2015 & $\mathrm{~N}$ & $\mathrm{~N}$ & Y & - & Y & Y & Y \\
\hline 5 & ALOS2050883050-150503 & May 3, 2015 & $\mathrm{~N}$ & $\mathrm{~N}$ & Y & Y & - & Y & Y \\
\hline 6 & ALOS2052953050-150517 & May 17, 2015 & $\mathrm{~N}$ & $\mathrm{~N}$ & Y & Y & Y & - & Y \\
\hline 7 & ALOS2059163050-150628 & June 28, 2015 & $\mathrm{~N}$ & $\mathrm{~N}$ & $Y$ & $Y$ & $Y$ & Y & - \\
\hline
\end{tabular}

"Y" and " $\mathrm{N}$ " represent "have" and "do not have" the potential for interferometric analysis (burst overlap > $20 \%$ ), respectively

If these cross-correlation peaks distribute uniformly, the largest peak is applied for the resampling (or transforming) process. However, if they do not, one part of the SLC may have a different peak from the others. This phenomenon causes the coefficients of the transformation function to be incorrect. One part of the master and the slave will be co-registered with one crosscorrelation peak; another part will be co-registered with another peak. Other parts will be co-registered between those peaks. If the master and the slave are co-registered between the two cross-correlation peaks, their interferogram contains no coherence. In short, a software for interferometric SAR processing fails to make a correct polynomial transformation function resulting in failure of making the interferogram.

Figure 3 is a sample of the histogram of the crosscorrelation between April 28, 2015, and March 31, 2015, of the path 47 (descending node) frame 3050. We divided each sub-swath of the ScanSAR image equally among three in the azimuth direction. Then, we distributed 100 windows and calculated the cross-correlation for each divided part. We applied $512 \times 512$ pixels for the correlation window. We round the cross-correlation results to the integer scale. As shown in Fig. 3a, there is only one major peak around 105-106 in sub-swath F1. On the other hand, in Fig. 3b, there are multiple peaks around 95 and 100-101 and the largest group is different between the top (north) and the bottom (south) part of the SLC. In this case, the software may make a failed transformation function. Figure 4a shows a sample of the failure of co-registration if the software had followed the peak distribution in Fig. 3b. In the middle sub-swath (F3), the fringes in the top of the SLC are perfectly connected to the neighboring sub-swaths. On the other hand, the fringes in the bottom part are not, although the coherency seems high. In this case, the master and the slave are aligned differently at the top and the bottom of the SLC by the different cross-correlation peaks. A co-registration error of 6 pixels results into a fringe rate of approximately 60 fringes across a typical interferogram.
There are several solutions for this problem. The easiest method is restriction of the affine transformation function. An ALOS-2 ScanSAR image contains negligible spatial distortions. That is, affine transformation function between the master and slave estimated from 32 times oversampled cross-correlation is almost linear or constant. Some softwares for interferometric SAR processing has higher (two or more) degree function for affine transformation, resulting in to fit transformation function to the multiple cross-correlation peaks. If we could restrict the degree of the function, for example $1^{\circ}$, and limit its coefficients so that the resampling would not exceed the single cross-correlation peak, we would obtain a clear interferogram as shown in Fig. 4b. Another solution is to use the SPECAN mode SLCs instead of the full-aperture mode ones.

\section{Subtracting remaining non-crustal fringes}

As in Stripmap interferometry, we subtract the orbital and topographic fringes from the interferogram in order to extract the deformation fringes. As the PALSAR2 ScanSAR image covers 350-km, non-crustal lowfrequency components, e.g., remaining orbital fringes and ionospheric fringes are visible.

In the case of an emergency observation, the orbital fringe sometimes is not accurate because the orbital data are not precise but calculated from the raw onboard GPS. Figure 5 shows the difference between the orbital fringe calculated from the onboard GPS and that from the precise orbit. The two orbits were not parallel, and the average baseline difference between these orbits was approximately $10 \mathrm{~m}$. From these results, we conclude that an interferogram made from the GPS onboard orbit may contain the remaining polynomial orbital fringes; however, these fringes can be subtracted by re-calculating the orbital fringes from the precise orbital data afterward. At the same time, the GPS onboard data satisfy the accuracy of ALOS-2 requirement. The error of the precise orbit of ALOS-2 is designed to be smaller than $0.1 \mathrm{~m}$, i.e., the orbital 
a

\section{Histogram of azimuth offset in F1}

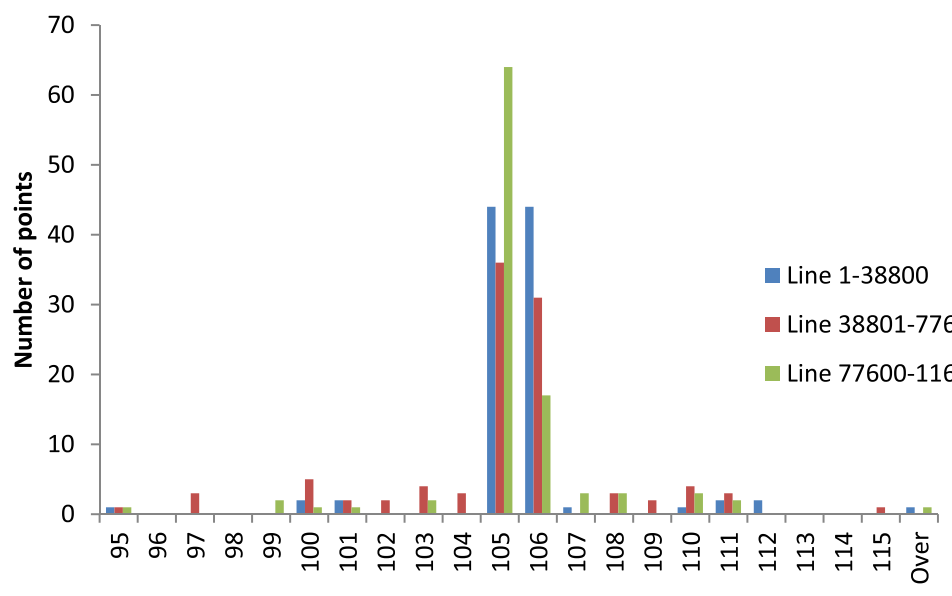

Azimuth shift

b

Histogram of azimuth offset in F3

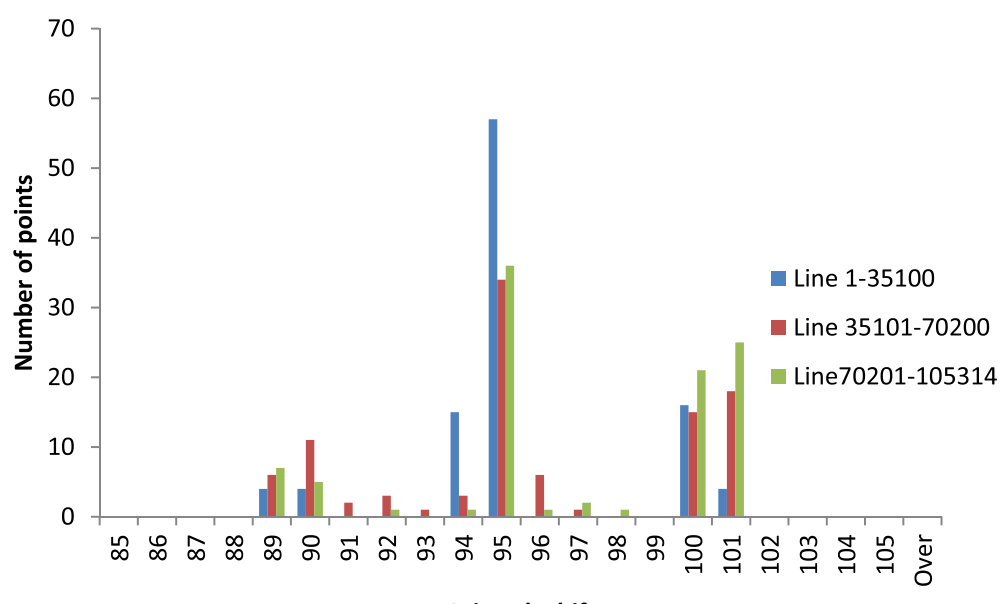

Azimuth shift

Fig. 3 Histograms of azimuth offset value plotted with cross-correlation peak. a Sub-swath F1 has a different peak. b F3 has multiple peaks
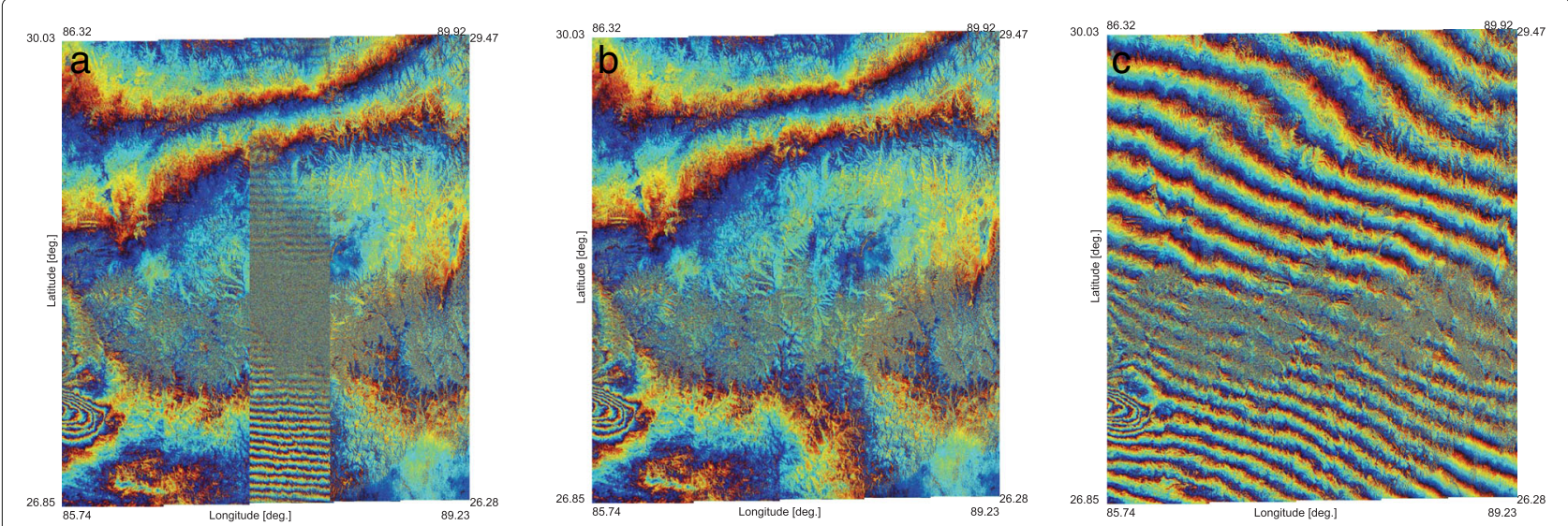

Fig. 4 Interferograms for coseismic deformation observed from path 47, descending. Path 47, frame 3050, deformation interferograms generated from frame 3050 on April 28, 2015, and March 31, 2015. a Failed interferogram in sub-swath F3 caused by misalignment of the transformation function. b Successful interferogram. c Interferogram without subtracting remaining non-crustal fringes 


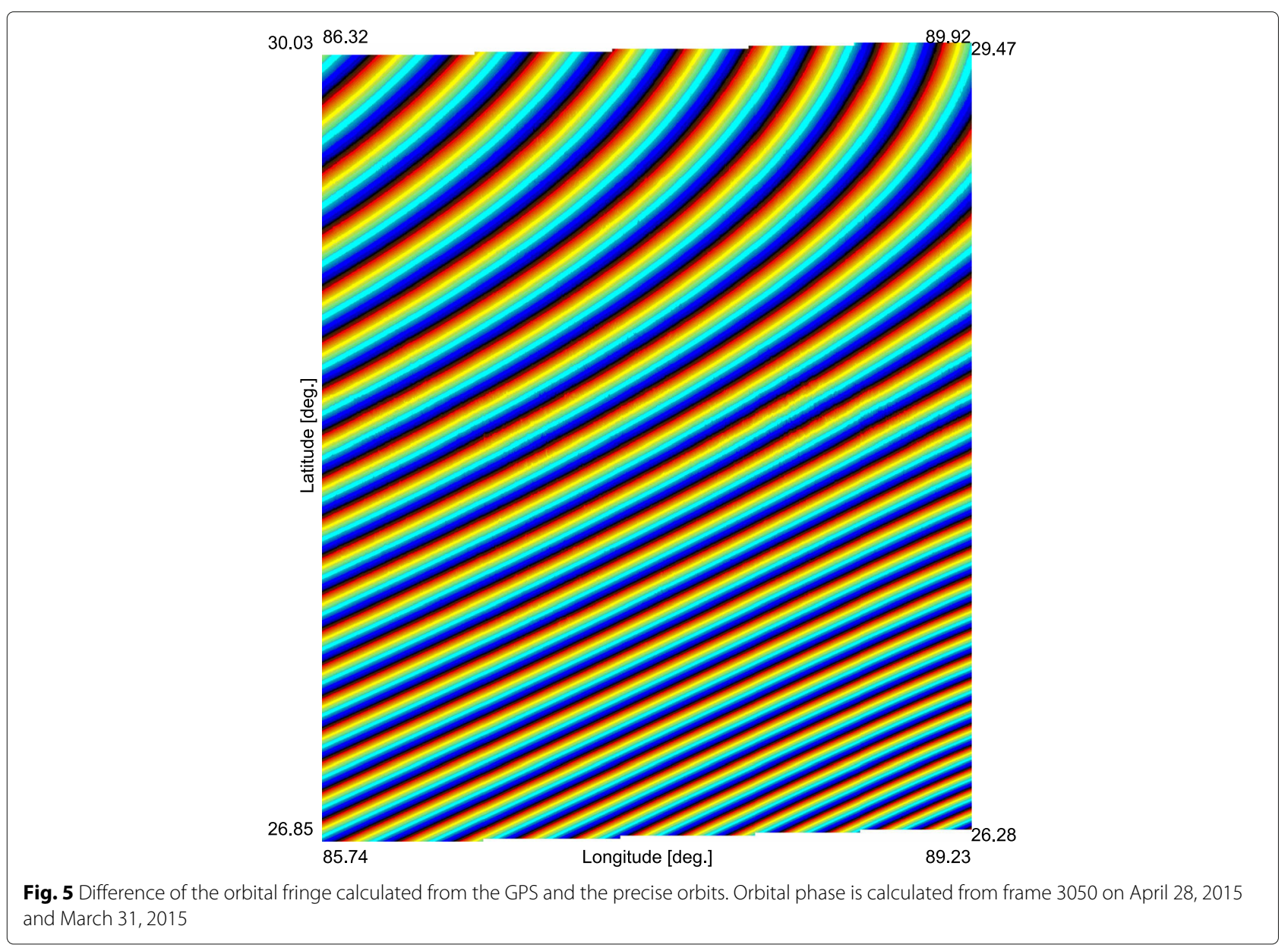

fringe calculated from the precise orbit contains negligible error.

Although we perfectly co-registered the master and slave SLCs and subtracted the orbital fringes, some fringes remain in the ScanSAR interferogram. Typically, ionospheric and atmospheric fringes are visible. A ScanSAR InSAR covers approximately $350 \times 350 \mathrm{~km}$, and the ionospheric effects appear at a scale of $10 \mathrm{~km}$ or more, while the atmospheric effects appear in a smaller scale. These effects are sometimes indistinguishable from crustal deformation fringes as shown in Fig. 4c. These low-frequency effects, especially the ionospheric effect which spreads in $100 \mathrm{~km}$ or more, can be subtracted by a $2^{\circ}$ or $3^{\circ}$ polynomial approximation. In Fig. $4 \mathrm{~b}$, we applied $1^{\circ}$ approximation so there are several remaining fringes. The atmospheric effect can be subtracted by GNSS delay and/or other atmospheric, especially humidity models (Bekaert et al. 2015; Doin et al. 2009), while the ionospheric effect can be calculated by splitting the radio band of the SLC as discussed in Gomba et al. (2015), Jung and Lee (2015), Jung et al. (2015), and Mayer et al. 2006.

Figure 6 shows the interferograms for path 48. Figure $6 a$ shows the deformation caused by the main shock.
In PALSAR-2 interferograms, one cycle of the fringe corresponds to approximately $12 \mathrm{~cm}$ of line-of-sight deformation. Figure 6a contains 10 fringes in its southern part, i.e., $1.2 \mathrm{~m}$ of displacement toward the satellite. From the northern fringe, the displacement was estimated to be as much as $84 \mathrm{~cm}$ away from the satellite. However, it is not clear whether it should be counted as it covers the Himalayan Mountains. The Himalayan topography makes it difficult to obtain coherent backscatter signal, resulting in possibility of a large line-of-sight (LoS) displacement model error. The width of the fringes expands $170 \mathrm{~km}$ in east-west direction. Figure $6 \mathrm{~b}$ shows the coseismic interferogram of the largest aftershock of Mw 7.3 on May 12, 2015 (USGS 2016b). This interferogram was calculated from the May 3 and May 17 observations. The result shows that the 14day revisit cycle of the ALOS-2 successfully separated the main shock and the aftershock. These interferometric pairs are analyzed and discussed more precisely in Diao et al. (2015), Kobayashi et al. (2016), Lindsey et al. (2016), and Wang and Fialko (2015). Especially, Kobayashi et al. (2016) use both ScanSAR-ScanSAR and StripmapScanSAR interferometry, that we will discuss in the next 

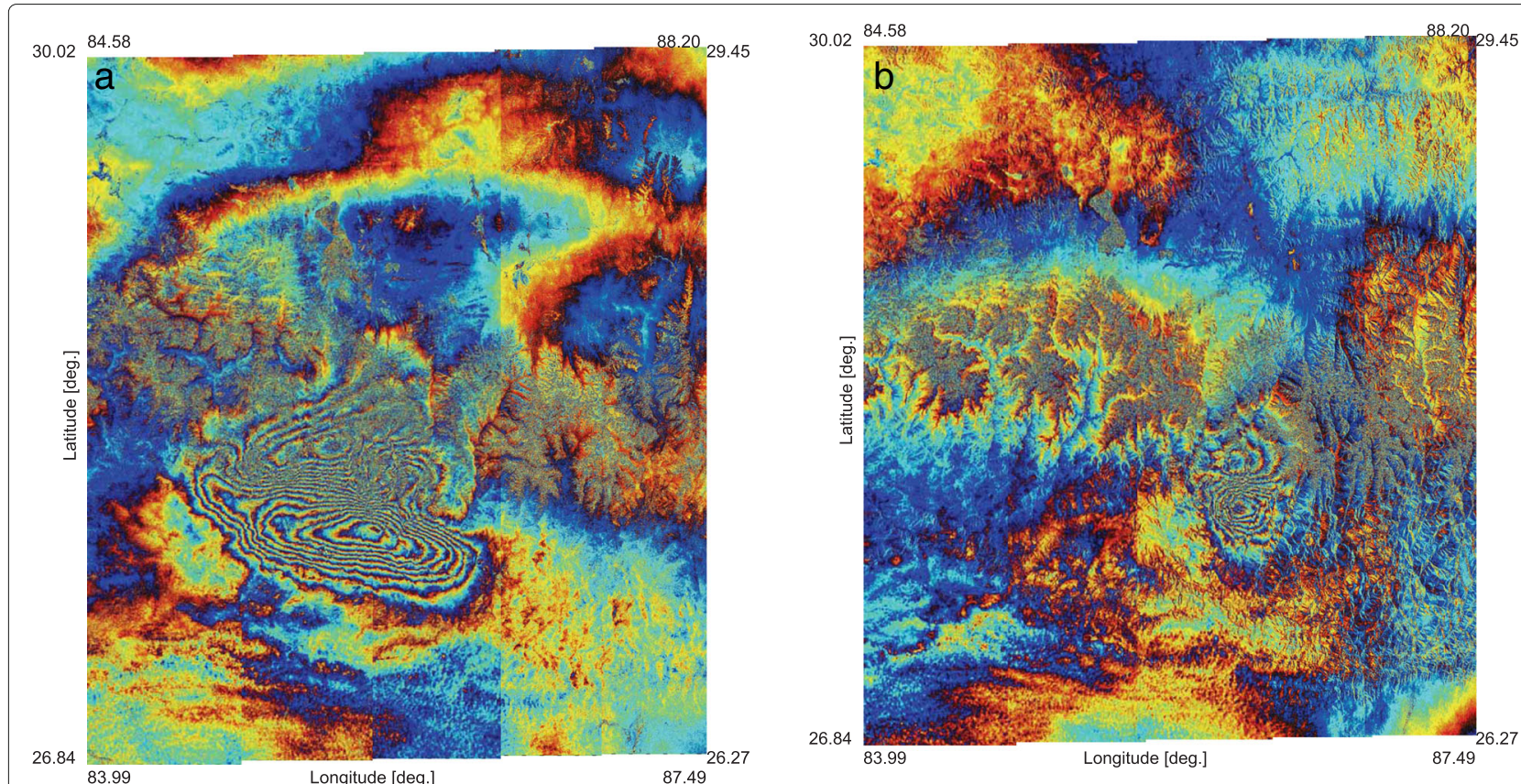

Fig. 6 Interferograms for coseismic deformation observed from path 48. Path 48 (descending), frame 3050, deformation interferograms generated from a frame 3050 on May 3, 2015-April 5, 2015 and b frame 3050 on May 17, 2015-May 3, 2015

section, for modeling the deformation and the fault rupture.

\section{Stripmap interferometry using fine mode beam no. F2-6}

Although paths 49, 156, and 157 have no ScanSAR archive available for ScanSAR-ScanSAR interferometric analysis, all the archives can be used for Stripmap-based interferometry. ALOS-2 basically observes the world with $10-\mathrm{m}$ resolution, $28-\mathrm{MHz}$ bandwidth, and $70-\mathrm{km}$ ground range observation width fine mode. The beam numbers are F2-5, F2-6, and F2-7. However, for the beam no. F2-6, there was an error derived from the incorrect setting of the radio center frequency (ALOS2 Project Team 2015a). The ALOS-2 can use multiple center frequency in L-band. For example, the spotlight

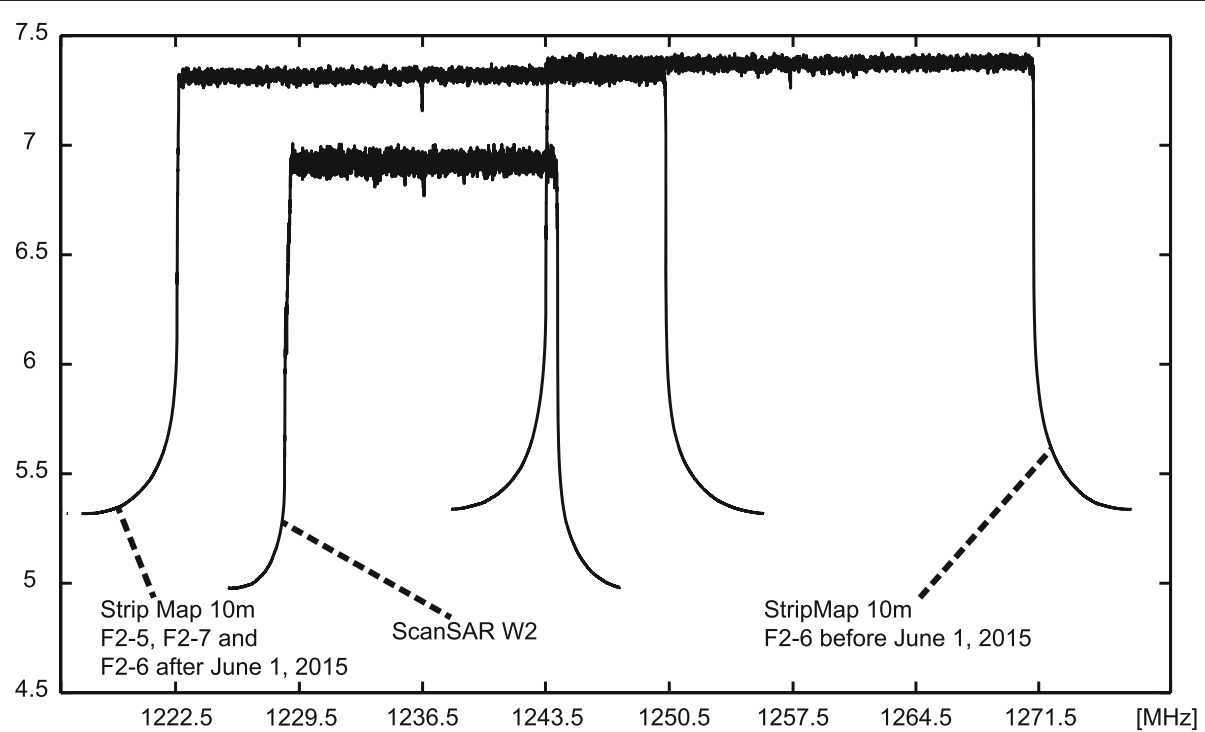

Fig. 7 Band overlap between Stripmap mode and ScanSAR mode. Beam F2-6 images had no overlap before June 1, 2015. Pre- and post-June 1 images for F2-6 have partial overlap. Note that the amplitude values in this figure are modified for ease of understanding 
mode and ultra-fine (3-m resolution, $84-\mathrm{MHz}$ bandwidth) modes use $1257.5 \mathrm{MHz}$, while the other modes including ScanSAR mode use 1236.5 MHz. However, the F2-6 SLCs were set in $1257.5 \pm 14 \mathrm{MHz}$ until June 1, 2015 while the other F2-5 and F2-7 were set in $1236.5 \pm 14 \mathrm{MHz}$. Figure 7 shows the plot of the range Fourier transformed L1.1 SLCs, i.e., frequency band overlap of the fine and ScanSAR mode. It is clear that there is no band overlap between ScanSAR and F2-6 before June 1. This is because the ScanSAR has only $1236.5 \pm 7 \mathrm{MHz}$ bandwidth and the difference of the center frequency between F2-6 is $21 \mathrm{MHz}$. At the same time,

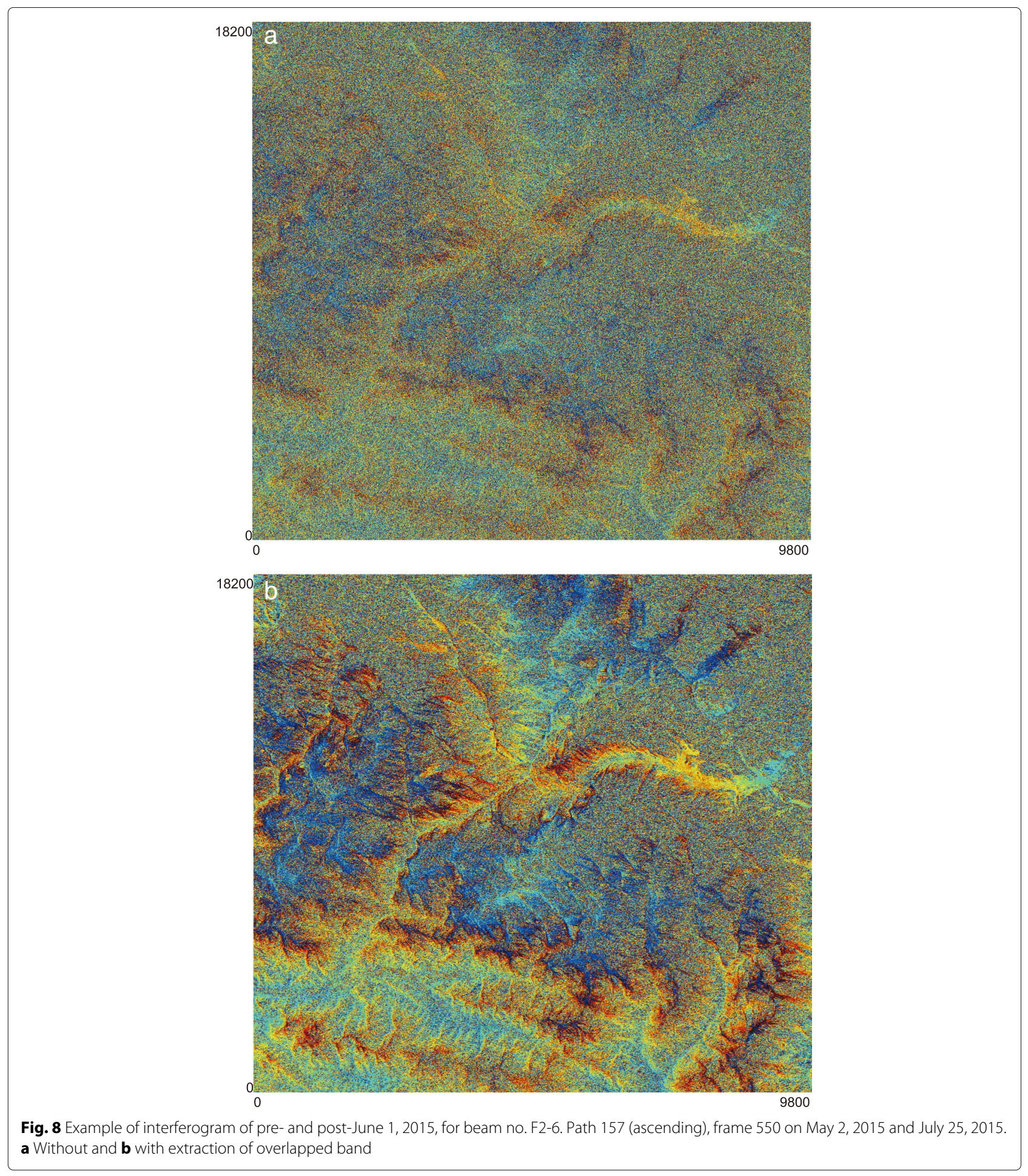


there are $7 \mathrm{MHz}$ remaining overlap between pre- and post-June 1 F2-6 images.

\section{Interferogram for pre- and post-F2-6 images}

Here, we present how to perform an interferometric analysis for the remaining $7-\mathrm{MHz}$ frequency band overlap. If we simply follow the step for creating an interferogram, non-overlapped bands hinder the interferometry. We have to cut 21 out of $28 \mathrm{MHz}$ from the original SLC data in advance.
First, we performed Fourier transformation in the SLC image in range direction to show its frequency band. Next, we apply the rectangular filter to extract the bottom and the top one-fourth bands from the pre- and the post-June 1 images, respectively. Finally, we calculate the inverse Fourier transform of the images and make an interferogram. The co-registration step can be performed either before or after this band extraction.

Figure 8 shows the comparison between with and without the band extraction operation. The improvement
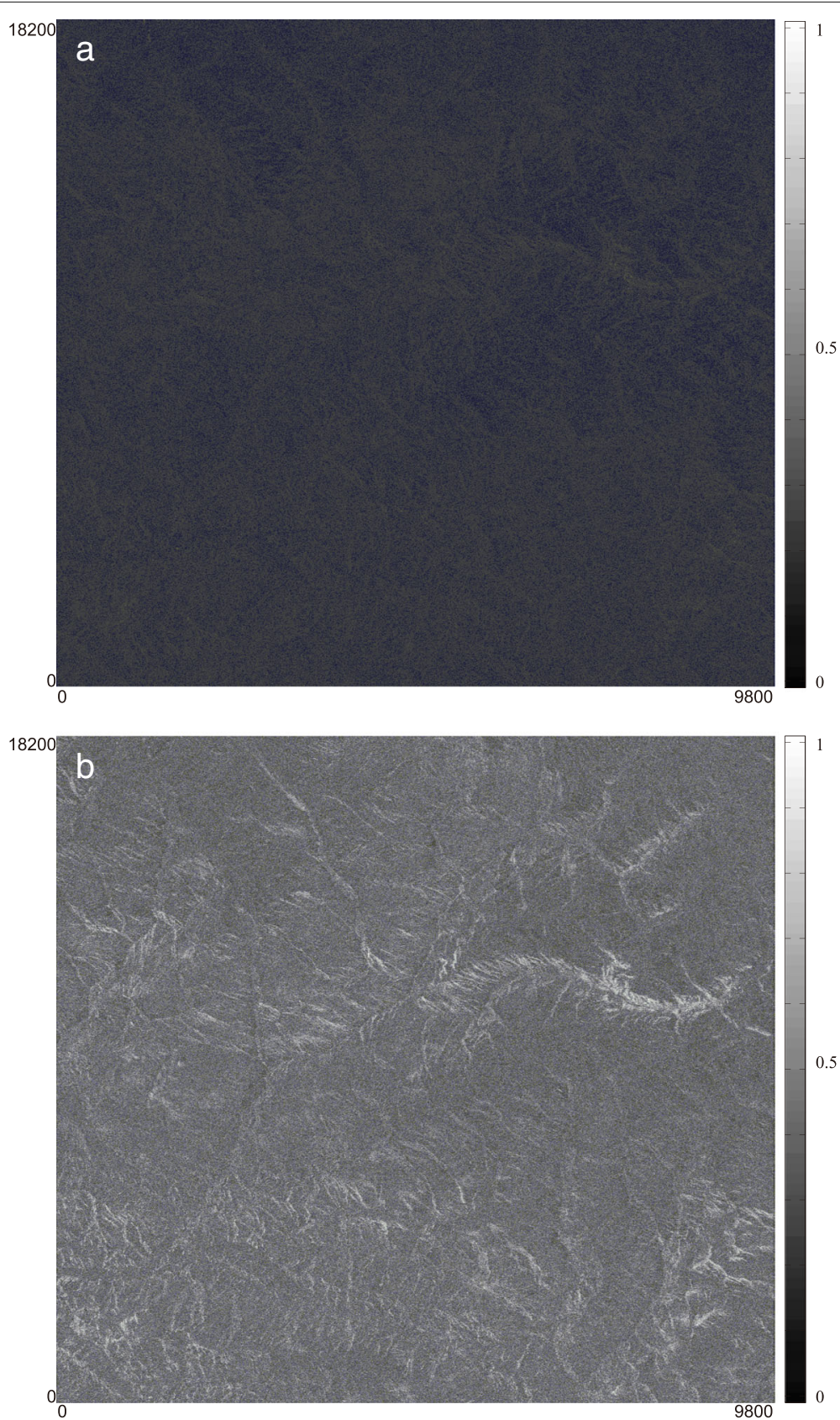

Fig. 9 Coherence images for Fig. 8. Path 157 (ascending), frame 550 on May 2, 2015 and July 25, 2015. a Without and b with extraction of overlapped band 


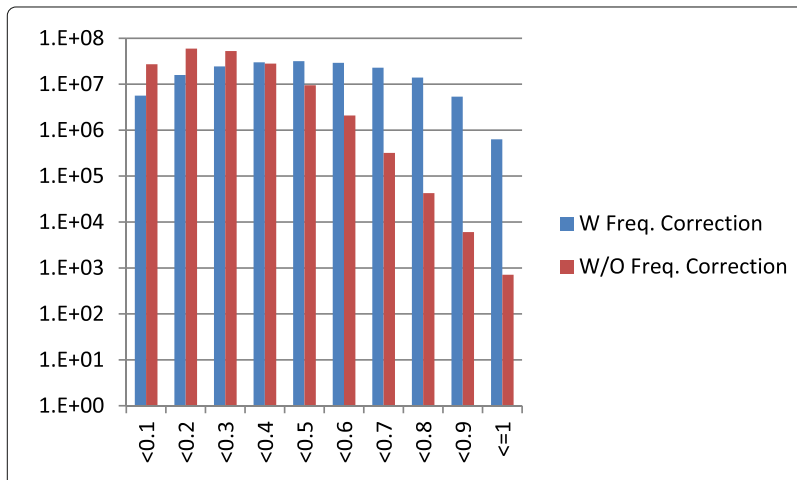

Fig. 10 Comparison of coherence value grouped at 0.1 intervals for Fig. 9. Mean coherence was doubled by extraction of overlapped band

of the interferogram is obvious. Figure 9 is the coherence images for the Fig. 8. Numerically, the average coherency increased from 0.21 to 0.44 . The histogram for the coherency value grouped at 0.1 intervals is shown in Fig. 10. On the other hand, this band extraction operation reduces the range resolution into $40 \mathrm{~m}$. It makes it difficult to detect small scaled deformation.

\section{Stripmap-ScanSAR interferometry}

As shown in Fig. 7, a ScanSAR image and Stripmap beam F2-5, F2-7, and post June 1, 2015 F2-6 images have frequency overlap. Here, we can make a StripmapScanSAR interferogram (Ortiz and Zebker 2007). In this case, a ScanSAR image can be used as same as a Stripmap image. One problem for performing a Stripmap-ScanSAR interferometry from L1.1 images is that they are observed with different PRF, range/azimuth sampling ratio (ratio of the ground distance per pixel), and coverage area in order to minimize the range and the azimuth ambiguity. That is, the PRF of the PALSAR-2 image depends on the off-nadir angle of the beam and the range sampling ratio depends on the frequency bandwidth. The azimuth sampling ratio is fixed for each mode if we use the L1.1 standard product.

In order to create a Stripmap-ScanSAR interferogram from the ALOS-2 L1.1 (SLC) standard products, their range and azimuth sampling ratio should be equalized before co-registration process. That is, we firstly resample the SLC so that Stripmap and ScanSAR images become the same range and azimuth sampling ratio. Generally, either Stripmap or ScanSAR images can be equalized to the other image. However, the coverage area for the Stripmap image is smaller than the ScanSAR and a ScanSAR L1.1 does not contain Doppler centroid information. For these reasons, we propose to resample the Stripmap image. If this resampling step is not performed, an accurate co-registration is impossible. Only if one can handle L1.0 (range compressed, not azimuth compressed)

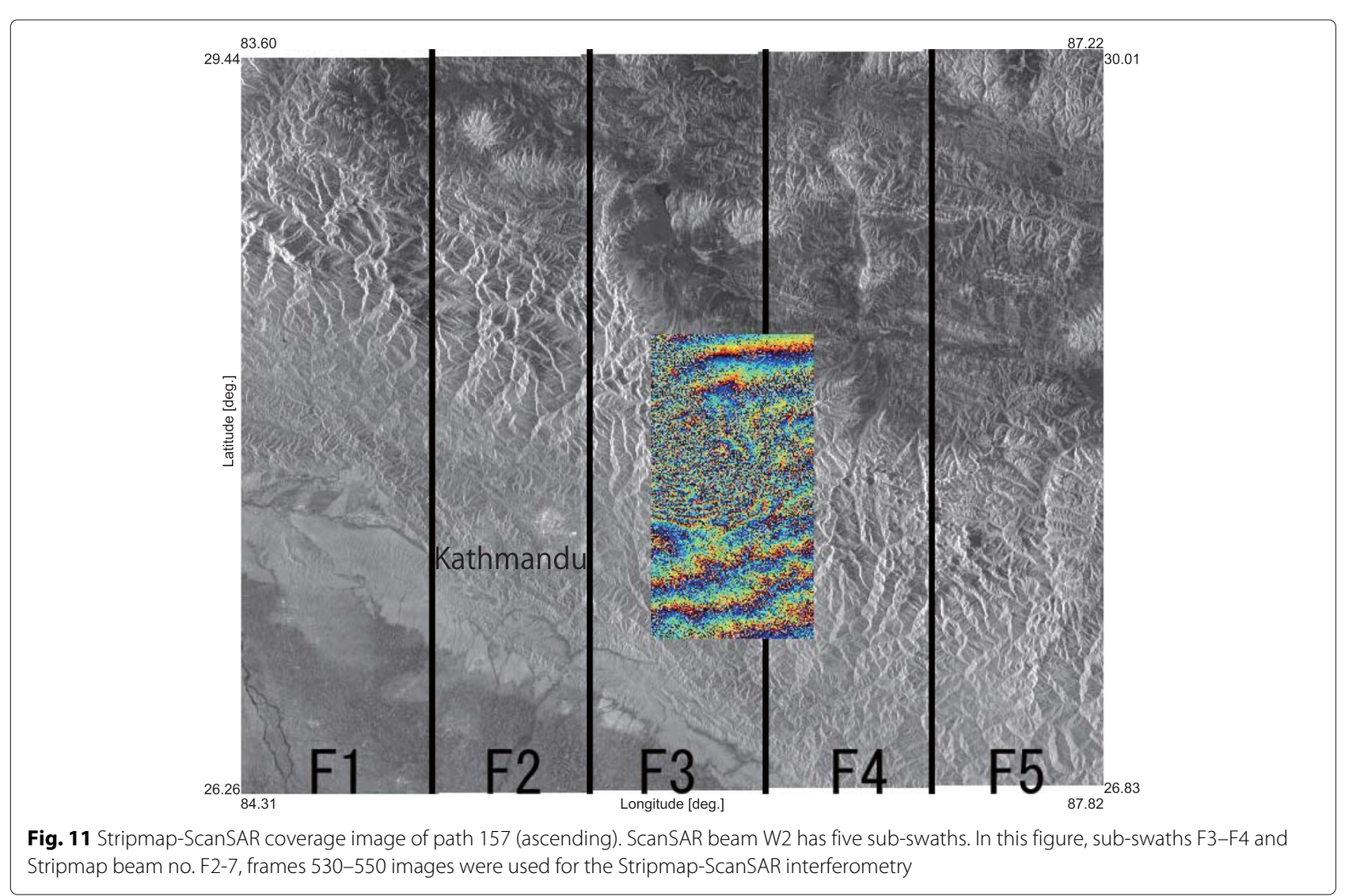


images, this step can be pretreated. However, JAXA does not provide L1.0 images for its policy currently.

Figure 11 shows a sample of the Stripmap-ScanSAR interferometry from L1.1 images. Here, path 157 (ascending) frame 550 observed on May 16, 2016 ScanSAR image and frames 530-550 observed on September 6, 2014 Stripmap images are used. The corresponding sub-swaths for the ScanSAR are F3 and F4, while the beam number of the Stripmap side is F2-7. The F1 and F2 correspond to the F2-5 and the F2 and F3 correspond to the F2-6, respectively. We extract the middle one half of the band from the Stripmap SLC so that the Stripmap SLC contains only the same band to the ScanSAR SLC.

Figure 12 is a closed-up image of the interferogram in Fig. 11. Here, we can see visible LoS displacements. Fringes are mostly connected between the border of the F3 and F4 sub-swaths and frames 530-550 of the Stripmap images. In the center part of the interferogram, a circle

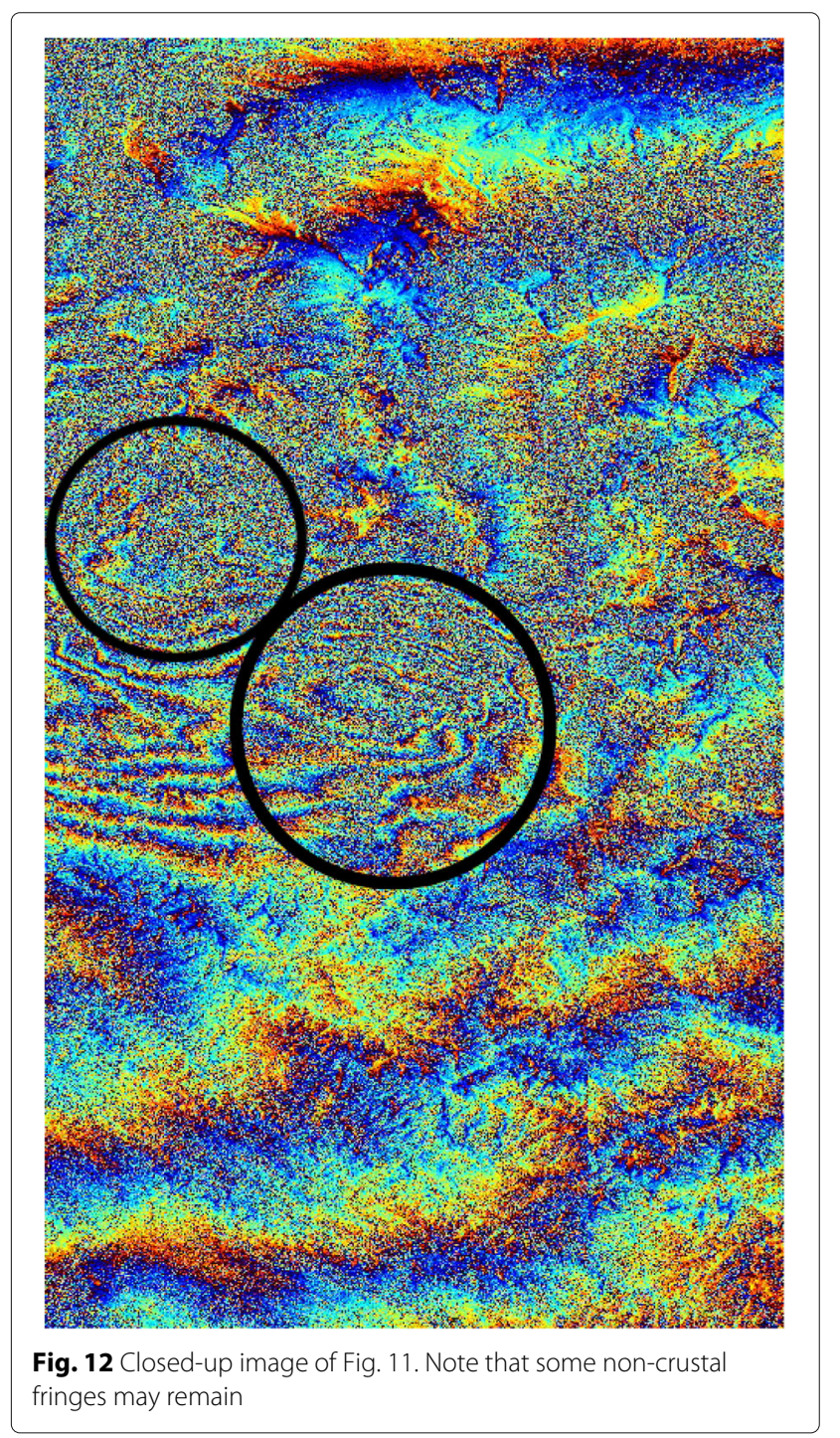

shaped deformation area is visible. It contains approximately 60-cm LoS caused by the aftershock on May 12 .

\section{Conclusions}

In this paper, we reported SAR interferometric analysis using PALSAR-2 ScanSAR data for the Mw 7.8 Gorkha, Nepal earthquake. Some operational errors were reported, and solutions to these problems were proposed. PALSAR2 ScanSAR observation enables us to analyze the coseismic deformation with a single SAR interferogram. However, in order to compute an accurate estimate of coseismic deformation, multiple interferograms are required. Unfortunately, ScanSAR-ScanSAR interferometric analysis using PALSAR-2 was only possible (available) for descending nodes for this earthquake. Using Stripmap images instead was required. We believe that this paper will facilitate interferometric analysis using ALOS-2 for coseismic and also interseismic deformation.

\section{Competing interests}

The authors declare that they have no competing interests.

\section{Authors' contributions}

RN headed the interferometric analysis. HN, RT, and TT collected the information from and intercommunicated with the affected area. $\mathrm{HN}$ also collected the ground truth data. RN, TM, MO, and MW examined the interferograms. RN, TM, and MS also analyzed the ScanSAR burst overlap problem. MS and SS managed this research. All authors read and approved the final manuscript.

\section{Acknowledgements}

The authors thank the Working Group for SAR Analysis, The Coordinating Committee for Earthquake Prediction Japan, for the early response to the Gorkha earthquake.

Received: 25 October 2015 Accepted: 21 January 2016

Published: 1 February 2016

\section{References}

ALOS-2 Project Team (2014) ALOS-2/PALSAR-2 Level 1.1/1.5/2.1/3.1 CEOS SAR product format description. http://www.eorc.jaxa.jp/ALOS-2/en/doc/ fdata/PALSAR-2_xx_Format_CEOS_E_r.pdf

ALOS-2 Project Team (2015) Change of the center frequency for the beam F2-6 in Stripmap Fine 10m Mode. https://auig2.jaxa.jp/information_home/ AUIG2_CenterFrequency_20151127_e.pdf

ALOS-2 Project Team (2015) Effective data for interferometric analysis with PALSAR-2 ScanSAR mode. https://auig2.jaxa.jp/information_home/ ScanSAR_Burst_Overlap_20151127_e.pdf

Arikawa Y, Saruwatari H, Hatooka Y, Suzuki S (2014) PALSAR-2 launch and early orbit operation result. In: Proceedings of International Geoscience and Remote Sensing Symposium (IGARSS) 2014. IEEE. pp 3406-3409

Bamler R, Eineder M (1996) ScanSAR processing using standard high precision SAR algorithms. IEEE Trans Geosci Remote Sensing 34(1):212-218

Bekaert DPS, Walters RJ, Wright TJ, Hooper AJ, Parker DJ (2015) Statistical comparison of InSAR tropospheric correction techniques. Remote Sensing Environ 170:40-47. doi:10.1016/j.rse.2015.08.035

Boerner WM (2003) Recent advances in extra-wide-band polarimetry, interferometry and polarimetric interferometry in synthetic aperture remote sensing and its applications. Radar, Sonar Navigation, IEE Proc. 150(3):113-124

Buckley SM, Gudipati K (2011) Evaluating ScanSAR interferometry deformation time series using bursted stripmap data. IEEE Trans Geosci Remote Sensing 49(6):2335-2342 
Cumming IG, Wong FHC (2005) Digital processing of Synthetic Aperture Radar data: algorithms and implementation. Artech House, 685 Canton Street Norwood, MA 02062 USA

Diao F, Walter TR, Motagh M, Prats-Iraola P, Wang R, Samsonov SV (2015) The 2015 Gorkha earthquake investigated from radar satellites: slip and stress modeling along the MHT. Frontier in Earth Science 65. doi:10.3389/feart.2015.00065

Doin MP, Lasserre C, Peltzer G, Cavalié O, Doubre C (2009) Corrections of stratified tropospheric delays in SAR interferometry: validation with global atmospheric models. J Appl Geophys 69:35-50. doi:10.1016/j.jappgeo.2009.03.010

Gomba G, Parizzi A, De Zan F, Eineder M, Bamler R (2015) Toward operational compensation of ionospheric effects in SAR interferograms: the split-spectrum method. IEEE Trans Geosci Remote Sensing:1-16. doi:10.1109/TGRS.2015.2481079 preprint

Guarnieri AM, Prati C (1996) ScanSAR focusing and interferometry. IEEE Trans Geosci Remote Sensing 34(7):1029-1038

Holzner J, Bamler R (2002) Burst-mode and scanSAR interferometry. IEEE Trans Geosci Remote Sensing 40(9):1917-1934

Jung HS, Lee WJ (2015) An improvement of ionospheric phase correction by multiple-aperture interferometry. IEEE Trans Geosci Remote Sensing 53(9):4952-4960

Jung HS, Lee DT, Lu Z, Won JS (2015) lonospheric correction of SAR interferograms by multiple-aperture interferometry. IEEE Trans Geosci Remote Sensing 51(5):3191-3199. doi:10.1109/TGRS.2012.2218660

Kankaku Y, Osawa Y, Suzuki S, Watanabe T (2009) The overview of the L-band SAR onboard ALOS-2. In: PIERS (ed). Proceedings of the Progress In Electromagnetics Research Symposium: August 18-21 2009. PIERS, Moscow. pp 735-738

Kobayashi T, Morishita Y, Yarai H (2016) Detailed crustal deformation and fault rupture of the 2015 Gorkha earthquake, Nepal, revealed from ScanSAR-based interferograms of ALOS-2. Earth Planets Space 67:201. doi:10.1186/s40623-015-0359-z

Lanari R, Hensley S, Rosen PA (1998) Chirp z-transform based SPECAN approach for phase-preserving ScanSAR image generation. Radar, Sonar and Navigation, IEE Proc. 145(5):254-261

Liang C, Zeng Q, Jia J, Jiao J, Cui X (2013) Scansar interferometric processing using existing standard insar software for measuring large scale land deformation. Comput Geosci 51:439-448

Lindsey EO, Natsuaki R, Xu X, Shimada M, Hashimoto M, Melgar D, Sandwell DT (2015) Line of sight displacement from ALOS-2 interferometry: M7.8 Gorkha earthquake and Mw 7.3 aftershock. Geophys Res Lett 42:6655-6661. doi:10.1002/2015GL065385

Mayer F, Bamler N, Jakowski R, Fritz T (2006) The potential of low-frequency SAR systems for mapping ionospheric TEC distributions. IEEE Geosci Remote Sensing Lett 3(4):560-564

Ortiz AB, Zebker H (2007) ScanSAR-to-Stripmap mode interferometry processing using ENVISAT/ASAR data. IEEE Trans Geosci Remote Sensing 45(11):3468-3480

Sack M, Ito MR, Cumming IG (1985) Application of efficient linear FM matched filtering algorithms to synthetic aperture radar processing. IEE Proc. 132(1):45-57

Shimada M, Osawa Y (2012) ALOS-2 science program and high resolution SAR applications. In: Proceedings of SPIE 8528: November 9 2012. p 852812 doi:10.1117/12.979379

Tong X, Sandwell DT, Fialko Y (2010) Coseismic slip model of the 2008 Wenchuan earthquake derived from joint inversion of interferometric synthetic aperture radar, GPS, and field data. J Geophys Res Solid Earth 115(B04314)

USGS (2016a) Event Page for the Gorkha Earthquake 2015. http://earthquake. usgs.gov/earthquakes/eventpage/us20002926

USGS (2016b) Event Page for the M 7.3 Aftershock of Gorkha Earthquake 2015. http://earthquake.usgs.gov/earthquakes/eventpage/us20002ejl

Wang K, Fialko Y (2015) Slip model of the 2015 mw 7.8 Gorkha (Nepal) earthquake from inversions of ALOS-2 and GPS data. Geophys Res Lett 42:7452-7458. doi:10.1002/2015GL065201

\section{Submit your manuscript to a SpringerOpen ${ }^{\circ}$ journal and benefit from:}

- Convenient online submission

- Rigorous peer review

- Immediate publication on acceptance

- Open access: articles freely available online

- High visibility within the field

- Retaining the copyright to your article

Submit your next manuscript at springeropen.com 